\title{
THE VALUE OF
}

A SPACE DISASTER

\section{ЦЕНA KOCMYYEQKOЙ \\ KATACTPOФb}


Boris V. PEVNITSKY, laureate the RF State Prize, the Chief of the Research Department of the Russian Federal Nuclear Centre (until April, 2013), Sarov, Saint-Petersburg, Russia, luda.pev@yandex.ru

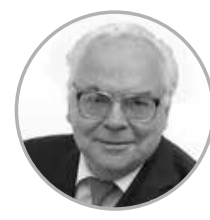

Борис Владимирович ПЕВНИЦКИЙ, лауреат Государственной премии Российской Федерации, до апреля 2013 года - начальник научно-исследовательского отдела Российского федерального ядерного центра - ВНИИЭФ, Саров, Санкт-Петербург, Россия, luda.pev@yandex.ru
ABSTRACT I In the article the "expected value" of the planetary defense system creation is considered. The question whether it is expedient for human civilization to implement this project is raised. The grounds why it is necessary to safe explosive technologies in the hypothetic "nuclear-free world" are give.

Keywords: a hazardous space object, planetary defense system, missile\&space and nuclear weapons technologies, expected value, nuclear-free world
АННОТАЦИЯ I В статье приводятся оценки величины «математического ожидания» последствий построения системы защиты Земли от опасных космических объектов. Ставится вопрос о целесообразности для человеческой цивилизации осуществления такого проекта и дается обоснование необходимости сохранения ядерных взрывных технологий в гипотетическом «безъядерном мире».

Ключевые слова: опасный космический объект (ОКО), система планетарной защиты (СПЗ), ракетно-космические и ядерно-оружейные технологии, математическое ожидание, безъядерный мир

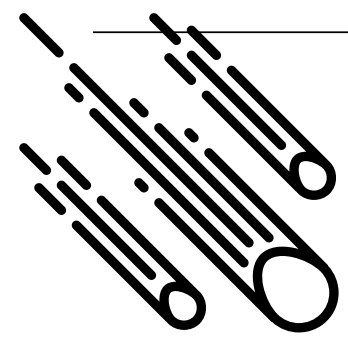

«Наши планетные геополитические разборки меркнут перед лицом угроз из космоса - астероидно-кометной опасности, солнечных бурь и вспышек».

Игорь Ашурбейли, «Воздушно-космическая сфера», № 1 (86), июль 2016.

«Если действовать рационально и по-человечески, если спокойно подойти к проблемам, стоящим перед лицом всего рода людского, если мы поймем, что нашими врагами являются совсем не соседи, а нищета, невежество и холодное безразличие к законам природы, - то все стоящие перед нами проблемы можно решить. Можно обдуманно сделать выбор и в итоге избежать катастрофф».

Айзек Азимов, «Выбор катастроф» (Isaac Asimov, "A Choice of Catastrofes") 


\section{ВВЕДЕНИЕ}

Столкновения небесных тел - естественные явления в Солнечной системе, во многом определяющие изменения их физических характеристик (элементов орбиты, вращения, формы поверхности, атмосферы и т.д.) [1, 2]. Они были в прошлом, наблюдаются в настоящее время и, несомненно, будут происходить снова.

Вопросы, связанные с защитой планеты Земля и ее жителей от опасных космических объектов (OKO), давно стоят на повестке дня и являются предметом обсуждений и дискуссий в научных журналах, на конференциях, симпозиумах [3]. Так, в статье генерального директора Центра планетарной защиты А. В. Зайцева «Незваный гость хуже Хеллоуина" дается характеристика современного состояния дел по проблеме [4]. В [5] представлено обоснование целесообразности применения снимаемых с вооружения межконтинентальных баллистических ракет шахтного базирования РС-2О «Воевода» в мирных целях. Предложено использовать их для запусков космических аппаратов в целях изучения космического пространства и пролетающих вблизи Земли астероидов, а также создания и отработки компонентов системы планетарной защиты (СПЗ) «Цитадель», предназначенной для предотвращения катастрофических столкновений с Землей астероидов и ядер комет.

\section{1. Стоимость Построения СПЗ}

Не в последнюю очередь игнорирование международным сообществом многочисленных предложений о развертывании широкомасштабной программы по созданию полноценной комплексной системы планетарной защиты от ОКО связано с кажущимися огромными затратами даже при широкой международной кооперации. На состоявшейся 30 июня 2018 года (в так называемый День астероида) пресс-конференции [6] была озвучена сумма затрат на организацию пилотного проекта СПЗ порядка десяти миллиардов долларов при сроке реализации в несколько лет. При этом имелось в виду использование уже существующих ракетно-космических, ядерно-оружейных и иных технологий. Но это было мнение сторонников процесса; противники будут пытаться обосновать более значительную сумму.

В интересах данной работы достаточно остановиться на предполагаемой величине этих затрат в интервале 10...20 миллиардов долларов. Сумма кажется невообразимой с точки зрения несведущего человека. Но ведь и вероятность катастрофического для цивилизации попадания ОКО в планету представляется ничтожной, едва ли не равной нулю. И при вычислении так называемого математического ожидания ущер- ба землянам мы практически сталкиваемся с неопределенностью типа "ноль, умноженный на бесконечность».

\section{2. Частота космических катастроф}

Но в действительности величины как вероятности катастрофы, так и затрат на отражение космической угрозы поддаются количественной оценке. Так, приведшее к вымиранию динозавров событие, связанное с попаданием астероида и образованием кратера Чиксулуб, случилось примерно 65 миллионов лет назад. Чиксулуб - древний ударный кратер диаметром около 180 км, находящийся на полуострове Юкатан и входящий в список крупнейших кратеров на Земле [7].

Предполагается, что кратер образовался в конце мелового периода в результате удара астероида диаметром около 10 км. Энергия удара оценивается в 100 триллионов тонн (!) в тротиловом эквиваленте. Отметим, что суммарная мощность всего термоядерного оружия на планете намного меньше (порядка нескольких миллиардов тонн).

Кратер Попигай (в Сибири, в бассейне реки Попигай, диаметр около 100 км) был образован в результате удара астероида 36 миллионов лет назад, в конце эпохи эоцена. Кратер Маникуаган в центральной части провинции Квебек, Канада, сформировался в результате столкновения с астероидом диаметром примерно $5 \mathrm{kм}$. Это событие произошло в конце триасового периода, 201 миллион лет назад.

Пучеж-Катунский 80-километровый кратер имеет возраст 170 миллионов лет.

Таким образом, можно полагать частоту катастрофических столкновений с Землей за период 50-10о лет (время жизни двух-трех поколений) равной одному разу в 50-10о миллионов лет. То есть вероятность катастрофического события, связанного с падением гигантского ОКО за период жизни двух-трех поколений, примерно равна одной миллионной.

\section{3. Материальный ущерб от космических катастроф}

И если понесенный человечеством материальный ущерб составит 100 триллионов долларов (оценочный суммарный валовой внутренний продукт за весь период жизни человечества), то "матожидание» $\mathrm{MO}_{1}$ ущерба от катастрофы действительно невелико, порядка 100 миллионов долларов. Но есть и другая оценка (см. таблицу) - дело ведь не в материальном ущербе, 


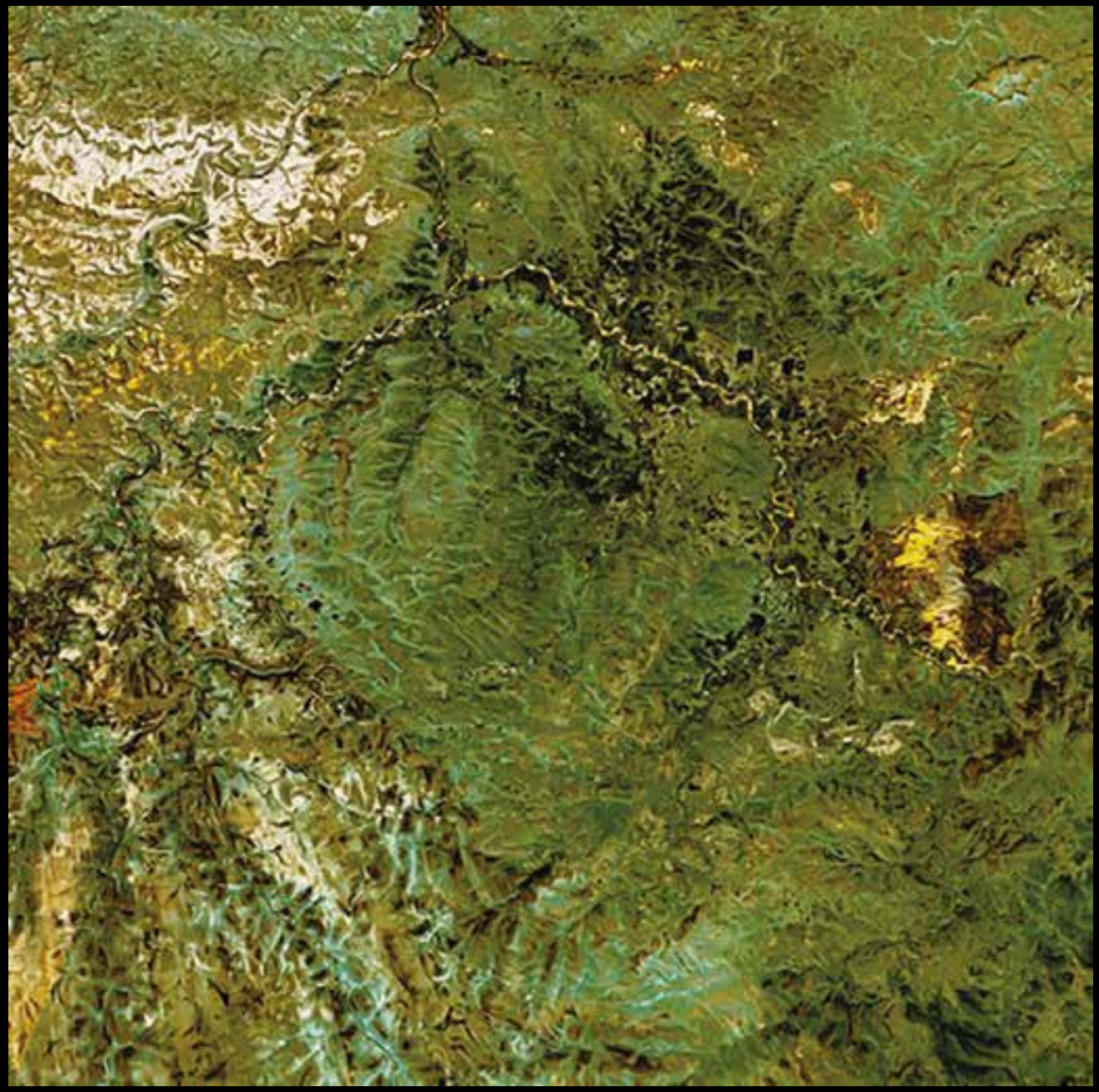

Puc. 1. Космический снимок Попигайского метеоритного кратера. Мозаччное изображение синтезировано из четырех сюжетов, полученных спутником Landsat 7 (США)

Суммарная мощность всего термоядерного оружия на Земле

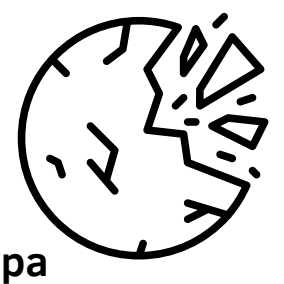
намного меньше, чем энергия удара астероида, в результате которого образовался кратер Чиксулуб. 
а в возможном исчезновении жизни на Земле. Если условно - в соответствии с рекомендациями Еврокомиссии, ЕРА, министерства транспорта США, CPSC, FDA и др. [8] - принять «стоимость» одной человеческой жизни в 3...9 миллионов долларов, то при нынешней численности населения Земли в 7,5 миллиардов "цена» всех ныне живущих жителей планеты составит несколько десятков квадриллионов (квадриллион - величина, равная десяти в пятнадцатой степени) долларов,

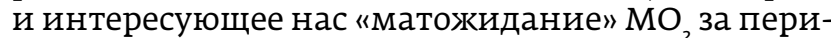
од в 50-100 лет становится существенно больше несколько десятков миллиардов долларов, что заметно превышает общие затраты на создание системы защиты Земли от ОКО.

\section{1. Мир без ядерного оружия, но с неприкосновенным запасом ядерных устройств}

В конце прошлого века прогрессивными учеными был поставлен вопрос о необходимости и неизбежности возникновения в обозримом будущем так называемого безъядерного мира, то есть мира без ядерного оружия (речь идет о всеобщем и полном ядерном разоружении). Не обсуждая здесь возможность и целесообразность такого глобального мероприятия, зададимся вопросом: как же быть с возможным мирным применением ядерного оружия или, точнее, мир-

\section{Табл. 1. Оценки вероятностей и «матожидания» последствий космической катастрофы}

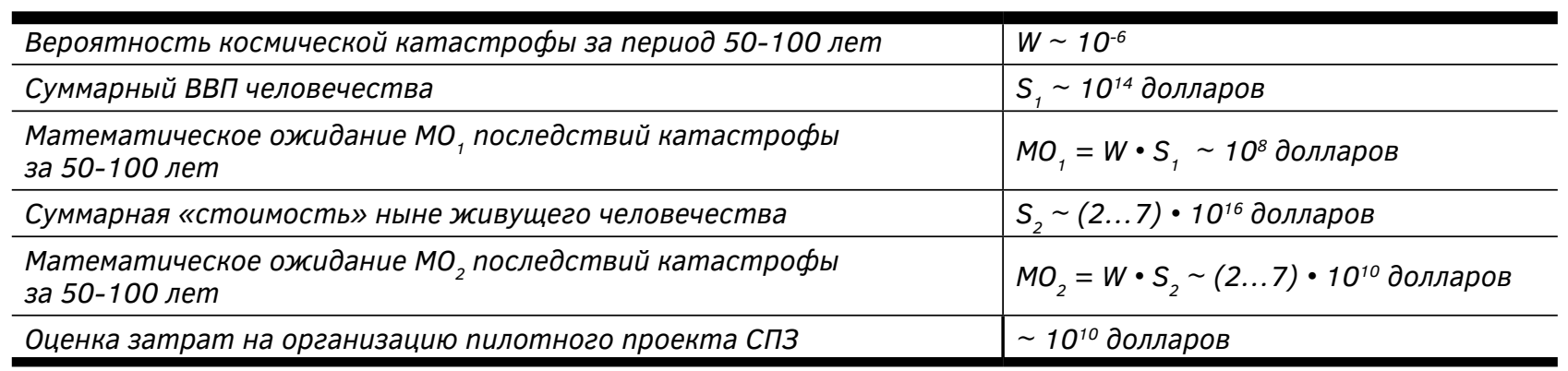

Разумеется, довольно безнравственно оперировать такого рода оценками. Ведь само существование человечества бесценно. Но тем более безнравственно самому человеческому сообществу из года в год игнорировать как астероидную опасность для бытия человеческой цивилизации, так и вполне реализуемый проект спасения от глобальной катастрофы.

Оставив в стороне вопросы о неопределенности тех или иных приведенных выше величин, можно утверждать, что человечеству, безусловно, более выгодно защитить себя от возможного исчезновения вследствие космической катастрофы, чем придерживаться страусиной политики выжидания, то есть заниматься лишь наблюдением за астероидами и кометами, изучением их свойств, проведением расчетов по воздействию на ОКО различных поражающих факторов, обсуждением возможных способов отражения угрозы и т. п.

Все перечисленное тоже необходимо как составная часть решения глобальной задачи, но совершенно недостаточно для реализации человечеством своей цивилизационной миссии на данном этапе технологического развития. ным использованием ядерных (термоядерных) взрывных устройств?

На конференции 2002 года в Комо (Италия) по проблемам безъядерного мира было заявлено [9]:

"...По меньшей мере безнравственно по отношению $\mathrm{k}$ последующим поколениям лишить их возможности применения при непосредственной угрозе возникновения глобальной катастрофы самого эффективного на сегодняшний день (и, скорее всего, еще на пару или более веков вперед) орудия самозащиты. Не исключено, что создание ядерного оружия имело и гуманитарную составляющую. Если предположить (что вовсе не исключено, хотя и маловероятно), что в ближайшие десятилетия астрономы обнаружат приближение к траектории Земли опасного космического объекта, способного нанести непоправимый ущерб цивилизации вследствие столкновения с планетой, то следует признать, что к тому моменту единственным реальным орудием противодействия могло бы оказаться лишь термоядерное взрывное устройство, способное изменить траекторию движения и тем самым позволяя избежать угрозы поражения всему живому. Оказавшись перед выбором - гибель цивилизации либо произведение термоядерного взрыва в космосе, 


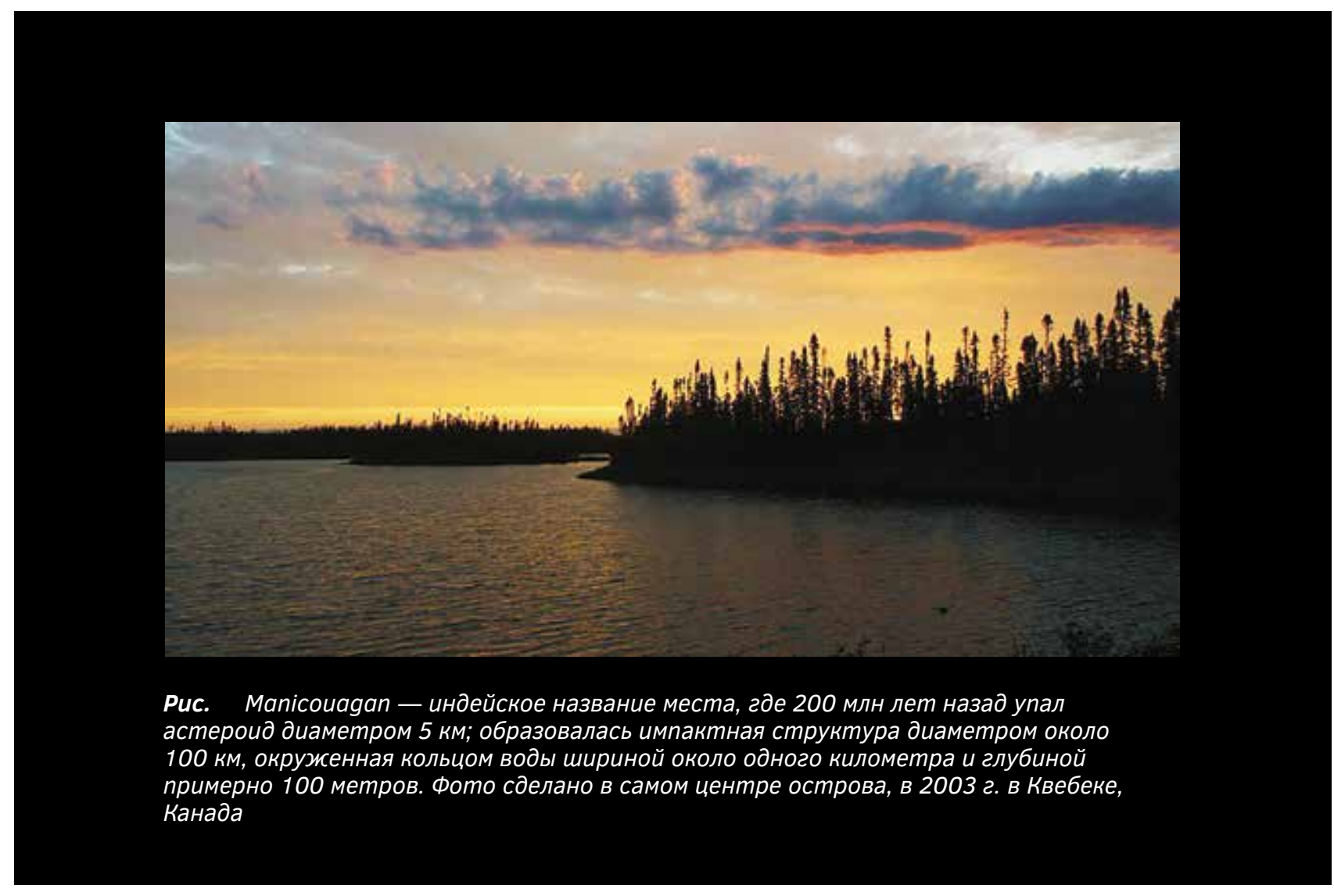

кстати, без каких-либо заметных экологических последствий для жителей Земли, - человек разумный (гомо сапиенс), безусловно, выберет второе. Безъядерный мир без неприкосновенного запаса ядерных устройств (НЗяу) может оказаться цветущей могилой человеческой цивилизации».

Помимо противоастероидной защиты Нзяу может оказаться необходимым:

- для предупреждения катастрофических землетрясений путем снятия напряжений в земной коре подрывом ядерного взрывного устройства (ЯВУ) [10];

- для срочного создания системы каналов для отвода вод при стихийных бедствиях глобального масштаба;

- для уничтожения больших количеств бактериологического оружия, мировых запасов вакцин или крупных очагов опасных прежде неизвестных инфекций;

- для интенсификации нефтяных, газовых или иных необходимых для человечества месторождений;

- для тушения глобальных пожаров на нефтяных скважинах [11];

- для подавления крупных очагов функционирования ядерных террористов.
Сегодня невозможно заранее предсказать, какие угрозы существованию цивилизации могут возникнуть через сотни или тысячи лет. И не факт, что к этому времени человечество будет обладать более мощным источником энергии, нежели термоядерное устройство.

Трудно предсказать также, каким будет безъядерный мир и возможен ли он вообще. В качестве возможной эволюции нынешнего мирового порядка может быть мир, полностью свободный от ядерного оружия, находящийся под управлением некоторой международной организации, аналога нынешней ООН, только с более широкими полномочиями. Эти полномочия должны будут включать в свой состав возможность применения методов принуждения по отношению к тем

Следует признать, что к моменту критической близости к Земле опасного космического объекта единственным реальным орудием противодействия может оказаться именно термоядерное взрывное устройство. 
членам мирового сообщества, которые попытаются нарушить согласованный миропорядок.

\section{2. Использование неприкосновенного запаса ядерных устройств}

В этих условиях возможно безопасное обладание необходимым международным НЗяу и соответствующими технологиями. Это может быть система расположенных в определенных разнесенных друг от друга местах складов или хранилищ, содержащих отдельные составные части ЯВУ. Эти составные части сами по себе не представляют никакой возможности для произведения ядерного взрыва сколь угодно малой мощности. Будучи же соединенными по определенному алгоритму в единое целое, они превращаются в полноценное ЯВУ. Команда на соединение отдельных частей и приведение полученного яВУ в действие может быть отдана только по решению специально на то уполномоченного органа в ситуациях, признанных чрезвычайными.

Разумеется, указанные склады и хранилища должны находиться в труднодоступных местах под максимально надежной защитой и охраной, исключающими несанкционированный доступ к находящимся в них элементам ЯВУ. Как это ни парадоксально, наиболее пригодными для этого местами могут быть территории нынешних «зон, свободных от ядерного оружия»: поверхность Луны, пустыня Сахара, Антарктида, морское дно, а также полости в горных массивах.

Очевидно, что процессу создания Нзяу будет предшествовать длительный переговорный процесс, имеющий своим позитивным итогом совокупность международных договоров и межправительственных соглашений о принципах построения и технических аспектах системы. В составе международного НЗяу могут находиться собираемые по модульному принципу - от меньшей ступени к все большим - явУ различных классов мощности. Разработка и изготовление таких ЯВУ будет проведена под международным кон-

\footnotetext{
Наиболее пригодными для хранения ядерных взрывных устройств местами могут быть территории нынешних «зон, свободных от ядерного оружия»: поверхность Луны, пустыня Сахара, Антарктида, морское дно, а также полости в горных массивах.
}

тролем широким кругом специалистов государств, обладавших в недалеком прошлом ядерным оружием. Сама конструкция яВУ должна подразумевать огромные сроки хранения ЯВУ в состоянии, годном для немедленной эксплуатации. Необходимо выработать критерии проверки надежности устройств при их длительном (сотни и тысячи лет) хранении. Подразумевается использование в конструкции яВУ специальных (пусть и чрезвычайно дорогих) материалов, способных к длительному функционированию. Придется решить множество задач по разработке соответствующих материалов и технологий борьбы со старением и потерей отдельных свойств этих материалов и сохранять некоторые предприятия по воспроизводству отдельных составных частей ЯВУ.

В случае принятия решения о необходимости применения ЯВУ той или иной мощности из имеющегося НЗяу специально обученные команды по специальным инструкциям производят на оборудованном для этих целей полигоне сборку и снаряжение явУ, размещают его на определенном носителе и в нужное время задействуют. Подготовка специалистов по обслуживанию и задействованию ЯВУ из НЗяУ производится в международных учебных заведениях по заранее составленным программам, предусматривающим как обучение необходимым дисциплинам, так и тренировки по обращению с ЯВУ и его составными частями.

Вопрос о воспроизводстве использованных ЯВУ с целью пополнения международного Нзяу неоднозначен. Если речь идет о маловероятных чрезвычайных событиях, угрожающих существованию цивилизации, то их повторение является событием с практически нулевой вероятностью. С другой стороны, спектр возможных угроз априори полностью неизвестен, и потребность в том или ином ЯВУ может возникнуть в любое время.

Разумеется, Нзяу должен находиться под непрерывным глобальным, исключающим малейшую возможность несанкционированного доступа хотя бы к отдельным его составляющим международным контролем, включающим лучшие на текущее время системы физической защиты, учета и контроля.

\section{ЗАКЛЮЧЕНИЕ}

Затраты на создание систем защиты планеты Земля от глобальной космической катастрофы полностью компенсируются парированием угрозы чрезвычайных последствий - полного уничтожения человеческой цивилизации. 


\section{Литература}

1. Уиппл Ф.Л. Семья Солнца. М.: Мир, 1984. 316 с.

2. Аткинсон 0. Столкновение с Землей: астероиды, кометы и метеороиды - растущая угроза. СПб.: Амфора, 2001. 398 c

3. Proceedings of the Planetary Defense Workshop (Lawrence Livermore National Laboratory, Livermore, California, 22-26 May 1995). Livermore, CA, 1995.

4. Зайцев А.В. Незваный гость хуже Хеллоуина // Военно-промышленный курьер. 2018. № 24.

26 июня. С. 12.

5. Бакланов О.Д., Бублий В.П., Галимов Э.М., Дремов В.В., Зайцев А.В., Махутов Н.А., Симоненко В.А. «Воевода» на страже планеты // Воздушно-космическая сфера. 2019. № 2. С. 32-39.

6. Зайцев А.В., Симоненко В.А., Шувалов В.В. Астероидная опасность: о предотвращении катастрофы накануне Тунгусского юбилея. Пресс-конференция (Москва, 29 июня 2018) [Электронный ресурс] // Национальная служба новостей. URL: https://youtu.be/o33StkuCuso (Дата обращения: 30.11.2019).

7. Полный каталог импактных структур Земли А.В. Михеевой. 3600 записей. ИВМиМГ СО РАН, последнее обновление 30 ноября 2019 г. [Электронный ресуpc]. URL: http://labmpg.sscc.ru/ (Дата обращения: 30.11.2019).

8. Быков А.А. О методологии экономической оценки жизни среднестатистического человека // Проблемы анализа риска. 2007. Т. 4. № 2. С. 178-191.

9. Бабичев Ю.Б., Лудин В.Н., Певницкий Б.В.

Международный неприкосновенный запас ядерных устройств (НЗяУ) и технологий, предназначенный для защиты цивилизации в безъядерном мире. Доклад на конференции по проблемам безъядерного мира. Комо, Италия, 2002 г.

10. Болт Б.А., Хорн У.Л., Макдональд Г.А., Скотт Р.Ф. Геологические стихии. М.: Мир, 1978. 440 с.

11. Андрюшин И.А., Богдан В.В. и др. Ядерные испытания СССР. Том 4. Использование ядерных взрывов для решения народно-хозяйственных задач и научных исследований. Саров, 2000.

\section{References}

1. Uippl F.L. Sem'ya Solntsa. Moscow, Mir, 1984, 316 p.

2. Atkinson 0. Stolknovenie s Zemley: asteroidy, komety i meteoroidy - rastushchaya ugroza. Saint Petersburg, Amfora, 2001, 398 p.

3. Proceedings of the Planetary Defense Workshop (Lawrence Livermore National Laboratory, Livermore, California, 22-26 May 1995). Livermore, CA, 1995.

4. Zaytsev A.V. Nezvanyy gost' khuzhe Khellouina. Voenno-promyshlennyy kur'er, 2018, no. 24,

26 June, p. 12

5. Baklanov O.D., Bubliy V.P., Galimov E.M., Dremov V.V., Zaytsev A.V., Makhutov N.A., Simonenko V.A. «Voevoda» na strazhe planety. Vozdushnokosmicheskaya sfera, 2019, no. 2, pp.32-39.

6. Zaytsev A.V., Simonenko V.A., Shuvalov V.V. Asteroidnaya opasnost': o predotvrashchenii katastrofy nakanune Tungusskogo yubileya (29 June 2018, Moscow). Available at: https://youtu.be/o33StkuCuso (Retrieval date: 30.11.2019).

7. Polnyy katalog impaktnykh struktur Zemli A.V. Mikheevoy. 3600 zapisey. IVMiMG SO RAN. Latest update 30 November 2019. Available at: http:// labmpg.sscc.ru/ (Retrieval date: 30.11.2019).

8. Bykov A.A. 0 metodologii ekonomicheskoy otsenki zhizni srednestatisticheskogo cheloveka. Problemy analiza riska, 2007, vol. 4, no. 2, pp. 178-191.

9. Babichev Yu.B., Ludin V.N., Pevnitskiy B.V. Mezhdunarodnyy neprikosnovennyy zapas yadernykh ustroystv (NZYaU) i tekhnologiy, prednaznachennyy dlya zashchity tsivilizatsii v bez"yadernom mire. Doklad na konferentsii po problemam bez"yadernogo mira. Komo, Italiya, 2002

10. Bolt B.A., Khorn U.L., Makdonald G.A., Skott R.F. Geologicheskie stikhii. Moscow, Mir, 1978, 440 p.

11. Andryushin I.A., Bogdan V.V. et al. Yadernye ispytaniya SSSR. Vol. 4. Ispol'zovanie yadernykh vzryvov dlya resheniya narodno-khozyaystvennykh zadach i nauchnykh issledovaniy. Sarov, 2000.

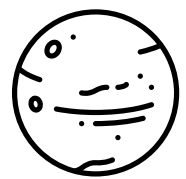

Модератор: Плетнер К.В. Конфликт интересов: отсутствует

Для цитирования:

Певницкий Б.В. Цена космической катастрофы // Воздушно-космическая сфера 2019. №4. С. 56-63. 